\title{
Online simulation for information technology skills training in higher education
}

\author{
Fatih Ari ${ }^{1}$ D $\cdot$ Ismahan Arslan-Ari ${ }^{1} \cdot$ Serdar Abaci ${ }^{2} \cdot$ Fethi Ahmet Inan $^{3}$
}

Accepted: 3 December 2021 / Published online: 29 January 2022

(C) The Author(s), under exclusive licence to Springer Science+Business Media, LLC, part of Springer Nature 2021

\begin{abstract}
The purpose of this study was to explore student's experiences when practicing information technology skills with an online simulation environment. After using the online simulation environment over a five-week period, 215 undergraduate students were surveyed regarding their usage-related experiences, satisfaction with the environment, and perceived learning. Both quantitative and qualitative data collection methods were employed. The quantitative results suggested that perceived ease of use had a direct effect on student's satisfaction with the online simulation environment, and that the satisfaction with the online simulation environment led to higher perceived learning. The qualitative findings revealed that technical problems, not being able to accomplish the objective of a step due to the precision required by the task, and the inflexibility of certain features of the online simulation environment were the commonly referenced issues, which might have impacted student's satisfaction and their perceived learning.
\end{abstract}

Keywords Online simulation · Information technology $\cdot$ Ease of use $\cdot$ Satisfaction Perceived learning $\cdot$ College students

Fatih Ari

arifatih@mailbox.sc.edu

Ismahan Arslan-Ari

arslanai@mailbox.sc.edu

Serdar Abaci

serdar.abaci@ed.ac.uk

Fethi Ahmet Inan

fethi.inan@ttu.edu

1 Department of Educational Studies, Wardlaw College of Education, Learning Design and Technologies Program, University of South Carolina, 820 Main Street, Columbia, SC 29208, USA

2 Moray House School of Education and Sport, University of Edinburgh, Edinburgh EH8 8AQ, UK

3 Texas Tech University, 2500 Broadway, Lubbock, TX 79409, USA 


\section{Introduction}

Online education offers many benefits such as flexibility and convenience which makes it a practical educational route for many students today (Bolliger and Martin, 2018). When learning online, learning is experienced within an intentionally designed environment where learners interact with instructors, other learners, and the teaching content through the internet using synchronous and asynchronous communication tools (Singh and Thurman, 2019). Despite its benefits, online learning also comes with challenges and different expectations for learners and instructors (Kebritchi et al., 2017). Kebritchi et al. (2017) identify "changing faculty roles, transitioning from face-to-face to online, faculty time management, and teaching styles" as main categories of instructor-related challenges for online teaching (p. 14). Online instructors should not only be able to deliver content but also use various technology and provide technological support for students, design student-centered learning experiences and be a facilitator of learning than a lecturer, communicate effectively and create opportunities for multi-level interactions in the online environment (e.g., student-student, student-instructor), and manage their time efficiently when preparing, planning, and teaching an online course (Dumford and Miller, 2018; Kebritchi et al., 2017). Further, assessing a significant amount of student work (Chen et al., 2016) and providing timely, individualized feedback (Lowenthal et al., 2019) have become a major issue for instructors when teaching high-enrollment online courses. As learner-related challenges for online learning, Kebritchi et al. (2017) offer four categories including "learners' expectations, readiness, identity, and participation in online courses" (p.7). Some learners may expect immediate feedback from their instructors on their online submissions (e.g., assignment, discussion post); some may not possess the required technical skills or time management and organization skills to be a successful online learner, and thus may not be ready for taking an online course; some may feel isolated and not connected to the learning community in an online course; or some may choose not to participate in learning activities or to interact with other learners in an online course (Kebritchi et al., 2017). All of these challenges can hinder effective online teaching and learning.

Despite the challenges, the enrollments in online courses in the U.S. continue to grow (Dumford and Miller, 2018; Skinner, 2019). Thus, almost every higher education institution has adopted a learning management system to support online teaching and learning (Way et al., 2021). According to a report by Dahlstrom, Brooks and Bichsel (2014), 99\% of the 800 higher education institutions that were surveyed in the U.S. reported that a learning management system has been adopted as an institution wide online learning platform. In addition, many college textbook publishers has been offering simulation environments (e.g., Pearson MyLab IT and McGraw Hill SIMnet) to support skill-based practice and assessment. Throughout this paper, we define online learning systems (OLSs) as systems that are utilized to support online teaching and learning by providing a learning platform, resources, tools, and support for instructors and students (Way et al., 2021) including learning management systems, online simulation environments (OSEs), e-learning systems; however, the body of this work is focused on OSEs. 
Previous research exploring the uses of OLSs in higher education mostly focused on the adoption of these systems (Al-Fraihat, Joy, Masa'deh, and Sinclair, 2020). Researchers have utilized either the original or the derivatives of Technology Acceptance Model (TAM) by Davis (1989) to explore the factors predicting behavioral intentions to use OLSs (e.g., Al-Azawei and Lundqvist, 2015; El-Masri and Tarhini, 2017; Islam, 2013; Persico et al., 2014). However, students' experiences and perceptions influenced by their interactions with these systems have not received as much attention in previous studies (Al-Fraihat et al., 2020). Therefore, further research is needed to better understand students' perspectives regarding their interactions with OLSs, and thus to meet their learning needs and expectations. Additionally, as the COVID-19 pandemic has forced many higher education institutions to move face-to-face courses into the online environment (Hodges et al., 2020), OSEs can be a viable solution for supporting teaching and learning in higher education, especially when the course outcomes focus on hands-on practice of gained knowledge and skills. Thus, during these unprecedented times, having greater insight into students' experiences with an OSE when gaining information technology skills in a high-enrollment, fully online undergraduate information technology course would yield useful information about how to support students' learning while they learn online using such systems.

\section{Theoretical background}

\section{Online simulation environments}

Computer simulations have been increasingly used in higher education in recent years (Chernikova et al., 2020). With the advancement of technology in the last decade, OSEs including online web-based simulations, virtual simulated labs, and virtual reality and immersive learning environments that simulates real-life settings have continued to evolve (Hallinger and Wang, 2020). In general, OSEs are such learning environments that model a real-life system or situation, computer software, a laboratory experiment setup, a business case, etc. to allow learners to practice skills and apply knowledge in a way similar to the real-life setting (Benckendorff et al., 2015; Hallinger and Wang, 2020). Studies showed that OSEs can be effective in promoting learning, facilitating higher order thinking, improving and sustaining learners' interest and motivation in a subject, and developing procedural skills (Chernikova et al., 2020; Makransky et al., 2019). OSEs can also assist instructors by providing automated and simultaneous feedback and enhancing student engagement in high-enrollment classes (Benckendorff et al., 2015). Although OSEs offer a great potential, there is still a need for further research in this area of study to improve students' learning and experiences in these environments (Thisgaard and Makransky, 2017). Furthermore, the majority of research exploring simulation-based learning in virtual environments come from the medical education and business education fields and relatively fewer studies from other fields such as teacher education, information technology, and management education (Chernikova et al., 2020; Way et al., 2021). Also, as OSEs should be considered for supporting teaching not as a replacement 
of a teaching method (Thisgaard and Makransky, 2017), exploring students' use of OSEs in unsupervised contexts and their experiences within these systems becomes of importance and interest (Makransky et al., 2019). Since the research with OSEs related to the focus of this work is scarce, in the following sections we synthesized the general OLS research relevant to our work to provide a sound rationale for the relationships between the constructs we explored in this study.

\section{Ease of use and perceived learning}

Davis (1989) defines perceived ease of use as "the degree to which a person believes that using a particular system is free of effort" (p. 320). Despite the plethora of studies suggesting positive influence of perceived ease of use on the adoption and future use of OLSs (e.g., Al-Rahmi et al., 2019; Alshurideh, Al Kurdi, and Salloum, 2019; Mohammadi, 2015; Nguyen et al., 2020; Rejón-Guardia, Polo-Peña, and Maraver-Tarifa, 2020), prior research is limited on examining the relationships between perceived ease of use and other learning related outcomes such as perceived learning and satisfaction with the learning experience (Al-Fraihat et al., 2020; Islam, 2013). To date, only a few studies that focused on the use of OLSs included learning related outcomes (e.g., perceived learning) as the main variable of interest in their studied research models (e.g., Al-Fraihat et al., 2020; Arbaugh, 2014; Ifinedo et al., 2018; Islam, 2013; McGill and Klobas, 2009; Weibel et al., 2012). In a recent study by Ifinedo et al. (2018), the researchers explored the determinants of the perceived use outcomes, including perceived learning assistance, academic performance, and perceived impact on learning, after undergraduate business students utilized an OLS in their courses. The findings from this study showed that perceived ease of use was one of the factors that impacted perceived use outcomes. In another study, McGill and Klobas (2009) studied the relationships between utilization of the OLS, task-technology fit, and perceived learning along with other variables (e.g., social norms). The findings from their study indicated that the utilization of the OLS had a direct influence on perceived impact on learning. In another study that used 48 online MBA courses, Arbaugh (2014) concluded that perceived ease of use of an OLS was a significant determinant of students' perceived learning. With university students from different colleges, Islam (2013) examined a model that included perceived ease of use, learning assistance, defined as the perception about the effectiveness of an OLS in assisting learning, and perceived academic performance. The results indicated that perceived ease of use significantly predicts perceived learning assistance, which in turn, predicts perceived academic performance (Islam, 2013).

In addition, previous research studies (e.g., Babu and Singh, 2009; Sahasrabudhe and Lockley, 2014) also reported the accessibility of OLSs as a barrier impacting learners' use of these systems. Most OLSs are designed for students without disabilities, and thus present accessibility barriers to students with disabilities (Iglesias et al., 2014). For instance, Sahasrabudhe and Lockley (2014) reported inappropriate text alternatives, availability of nested tables, variance in the user interface, difficulty in keyboard use for navigation, improper reading order, and ambiguous instructions as the accessibility and usability issues of an OSE. These issues hindered students' 
access to the content and the completion of the tasks which directly impacted students' performance.

Although these studies have not focused on OSEs particularly, except for the Sahasrabudhe and Lockley (2014) study, the results of these studies suggest that perceived ease of use may influence, either directly or indirectly, students' perceptions of their learning in an online learning environment.

\section{Satisfaction and perceived learning}

Satisfaction plays a crucial role in academic success (Bolliger and Martindale, 2004; Karimi and Ahmad, 2013). In its simplest form, satisfaction is defined as the feeling of accomplishment when the demonstrated performance towards the completion of a task is consistent with the performer's expectations (Keller, 1983). Keller (1983) considers satisfaction as one of the sub-dimensions of an individual's overall motivation. Consequently, satisfaction contributes to developing intrinsic motivation as well as to sustaining overall motivation during the learning process (Small and Venkatesh, 2000).

Several studies point to a significant relationship between satisfaction and learning performance (Cakir and Solak, 2014; Ifinedo et al., 2018; Karimi and Ahmad, 2013; Pérez-Pérez et al., 2020). In a study with high school students who took an online English course, Cakir and Solak (2014) found that satisfaction was amongst the significant predictors of students' academic achievement. Similarly, Karimi and Ahmad (2013) found significant correlation between pre-service teachers' perceived learning and satisfaction with their learning experience in a blended teacher education program. In addition, a study by Pérez-Pérez et al. (2020) revealed that students' satisfaction with an OLS in an undergraduate operations management course was the most significant determinant of their perceived learning outcomes. Therefore, as suggested by Bradford (2011), studying satisfaction is important to understand students' learning experiences in an online learning environment.

\section{Ease of use, frustration, satisfaction, and perceived learning}

OLSs that are perceived difficult to use may lead to frustration and anxiety (Naveh, Tubin, and Piliskin, 2012). Learners may feel frustrated when a system does not respond to their actions as expected, preventing them from accomplishing a goal (Ceaparu et al., 2004; Keller, 2008; Lazar et al., 2006). Previous research has shown that experiencing frustration as learners interact with a learning system impacts their satisfaction with the learning system (Green, Inan, and Denton, 2012; Sun et al., 2008; Yang and Dorneich, 2018) and their learning experiences negatively (Ifinedo et al., 2018; Yang and Dorneich, 2018). Among the various causes of frustration, poor interface design, system functionality (e.g., software failures), and system quality (e.g., accessibility, reliability) have been associated with a system's ease of use (Lazar et al., 2006). Research also supported that system functionality and quality are critical factors affecting students' satisfaction with learning systems (Haddad, 2018; Joo et al., 2011; Mtebe \& Raphael, 2018; Ozkan and Koseler, 2009; 
Pérez-Pérez et al., 2020; Wu et al., 2010). Ozkan and Koseler (2009), for instance, suggested that the interface of an e-learning system should be user-friendly for sustaining learner's satisfaction. In a recent study, Pérez-Pérez et al. (2020) also reported the system quality, defined as the learning system's accessibility and reliability, as one of the most relevant factors to explain students' satisfaction. Furthermore, Sun et al. (2008) emphasized the importance of system quality and functionality by concluding that assessing a learning system's performance and functionality periodically may enhance student satisfaction.

In addition to satisfaction, the frustration caused by the factors related to a learning system's ease of use may hinder learning. OLSs that are perceived to be difficult to use may require learners to invest more effort in learning how to use the system rather than in completing the learning tasks (Davis et al., 1992), which leaves limited cognitive resources for learning. Furthermore, when learners experience frustration caused by system-related disappointing events (e.g., software failure), their "cognitive flow" can be interrupted, resulting in "negative cognitive loop" (Baker et al., 2010, p. 237) which may require them to invest unnecessary cognitive effort in non-learning related issues. Also, Baker et al. (2010) stressed that the frustration is a "cognitive-affective state" meaning that both cognition and emotions experienced by the students contribute to the feeling of frustration, and thus the interface design of learning systems that are sensitive to both affective and cognitive states may be perceived more usable and enjoyable (p.224). However, when the interface of a learning system is perceived to be complex to use (e.g., searching for menu items), it might easily overload the learners' limited working memory capacity and cause extraneous cognitive load (Furtado et al., 2019). When learners use their working memory capacity for figuring out how to use the system, fewer cognitive resources are left to process the essential knowledge being learned, which in turn, would impair their learning (Mayer, 2020). To sum up, when an OLS is easy to use, students may not need to spend extra effort to master the features of the system (Islam, 2013). Students would demonstrate higher satisfaction with an OLS and with their overall learning experience if they achieve satisfactory results and find their efforts reasonable to complete the learning tasks within the system (Sun et al., 2008).

\section{Purpose of the study}

This study aimed to make several contributions to the literature on online learning environments. First, despite the wealth of research on the use of OLSs in higher education, there is a gap in the research literature exploring students' experiences with OSEs in higher education. Therefore, this study aimed to contribute to this area of research by exploring undergraduate students' experiences with an OSE designed for practicing Microsoft Office applications. Second, the majority of studies exploring the use of OLSs have utilized TAM or TAM-like approaches employed quantitative methods mostly and focused on users' adoption of these systems (Al-Emran et al., 2018). Therefore, this study aimed to contribute to research literature by utilizing a mixed-methods approach to provide a richer understanding of students' experiences with the OSE. Lastly, during the current COVID-19 pandemic, the findings 
from this study are very timely and useful for the online instructors who consider adopting an OSE in their courses and for practitioners who design OSEs.

In this sense, the purpose of this study was to explore students' experiences with an OSE designed for practicing Microsoft Office applications. The following research questions guided this study:

1. What are the relationships between perceived ease of use, satisfaction with the OSE, and perceived learning?

2. What are the students' perceptions of and experiences with the OSE?

\section{Method}

This study implemented a cross-sectional survey design to explore the relationship between perceived ease of use (PEU), satisfaction with the OSE (SAT), and perceived learning (PL), and to explore the students' experiences within an OSE. First, this study employed a structural equation modeling (SEM) approach to test the relationships between the study variables. A conceptual model (see Fig. 1) was initially developed based on the literature, and the following hypotheses were tested using the SEM approach to answer research question one.

H1 Perceived ease of use of the OSE is positively associated with perceived learning.

H2 Perceived ease of use of the OSE is positively associated with satisfaction with the OSE.

H3a Satisfaction with the OSE is positively associated with perceived learning.

H3b Satisfaction with the OSE mediates the effects of perceived ease of use on perceived learning.

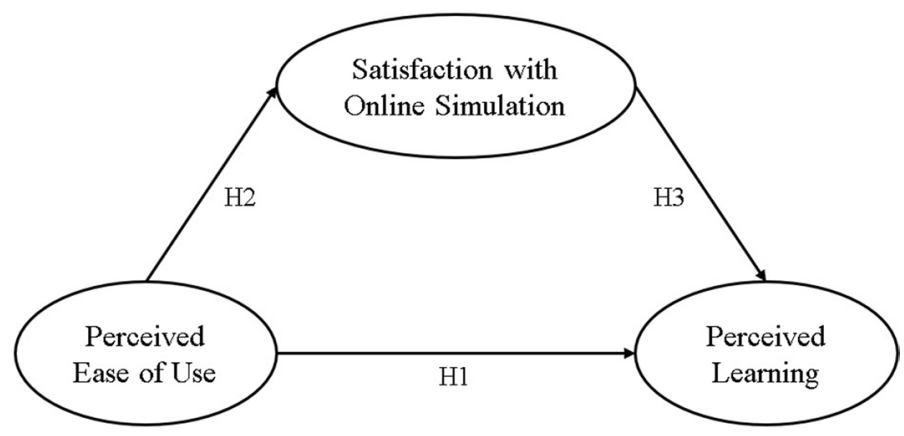

Fig. 1 Conceptual model of the study 
Quantitative data was collected through an online survey with demographic questions and multiple items for each of the three variables. Data preparation and descriptive analysis such as normality check and instrument reliability were performed using SPSS version 24 while SEM analyses were completed using Mplus 7.31 .

Qualitative data was collected through several open-ended questions in the online survey. These questions were aimed at answering the second research question regarding the students' experiences with the OSE in general, and with some of its instructional support features. This qualitative data was analyzed using open coding and frequency counts. Two of the researchers created an initial codebook, and they each coded independently a sample of 70 participants' responses in Microsoft Excel. The results of the interrater reliability calculation showed a high level of agreement between the researchers $($ Kappa $=0.94)$. Then, only one researcher continued analyzing the rest of the qualitative data.

\section{Participants}

Two hundred and fifteen undergraduate students (108 females and 107 males) volunteered to participate in the study. The students were enrolled in a fully online information technology course at a large southwestern university in the United States and received course credit for their participation. Since this course was offered to all majors at the university, participants came from different disciplines and their ages $(M=20.11, S D=1.93)$ ranged from 18 to 30 with a median age of 20 . In terms of academic classification, $29.8 \%$ of the participants were freshman, $36.7 \%$ were sophomore, $25.6 \%$ were junior, and $7.9 \%$ were senior. Regarding ethnicity, the majority of them were White (72.1\%), followed by Hispanic (14.9\%), African American (7.4\%), Asian (4.7\%), and Native American (0.9\%). Approximately $80 \%$ of the participants reported that they use computers and the internet for at least six hours per day. In addition, $65.1 \%$ of the participants reported that they had not used a similar OSE before taking this course. In terms of their perceived technical skills, $57.7 \%$ of the participants rated themselves good, $23.3 \%$ as moderate, $17.2 \%$ as very good, and $1.9 \%$ as poor.

\section{Procedure and study materials}

The participants completed four learning modules over a five-week period. There were 10 online assignments covering various skills in Microsoft Word (e.g., formatting a table in different ways) and Excel (e.g., calculating the average score of a list of numbers). The assignments were delivered through an OSE, which provided the participants with an interface that emulates the Microsoft Word and Excel applications. To complete each assignment, the participants performed a series of tasks (e.g., insert a table, add a column, add a row, etc.) as they would do in the actual applications. Furthermore, the OSE provided learners with instructional support such as demonstration (i.e., Show Me), guidance (i.e., Hint), and flexibility (i.e., Save for Later). When activated, the Hint feature guided students through the steps 
of an assignment by allowing them to complete each step with instructions and support (e.g., an arrow pointing a menu item to click on) provided. Upon completion of all the steps of an assignment with the Hint feature, the students needed to perform the steps again to complete the assignment. Unlike the Hint feature, the Show Me feature did not allow students to complete each step hands-on, but it demonstrated how to carry out the steps in sequence, similar to a screen capture, to complete an assignment. In addition to these two support features, the OSE provided students with the option of saving the completed portion of their work using the Save for Later feature. For each assignment, the participants had unlimited attempts. After working on the assigned learning modules, the participants completed an online survey anonymously. They received unlimited time to complete the survey.

\section{Instruments}

The online survey comprised five sections: demographics, perceived ease of use, satisfaction, perceived learning, and open response items (See Appendix for a full list of quantitative and open response items). Perceived ease of use, satisfaction and perceived learning sections included Likert-type questions, which required responses to items on a 5-point scale ( $1=$ Strongly Disagree, $2=$ Disagree, $3=$ Neutral, $4=$ Agree, and $5=$ Strongly Agree) .

Perceived ease of use was measured using nine items such as "I thought the online simulation environment was easy to use." The items were adapted from Brooke's System Usability survey (1996). The internal reliability of the survey items was good (Cronbach's $\alpha=0.79$; Nunnally and Bernstein, 1994). After reversing the scale for negatively worded items, we averaged these nine items into a single index by taking the mean of responses because items represented a single dimension as the measurement model of the perceived ease of use construct was not the main focus of this study. This was a decision the researchers made during the model specification in order to satisfy the minimum sample size requirement for anticipated effect size and power, which is justified in the debate on the value and adequacy parceling in SEM (Little, Cunningham, Shahar, and Widaman, 2002).

Student satisfaction with the OSE was measured using the satisfaction subscale of Keller's Instructional Materials Motivation Survey (Keller, 1993), which included five items such as "Completing the assignments in [OSE] gave me a satisfying feeling of accomplishment." The internal reliability of these survey items was good $(\alpha=0.80)$.

Perceived learning was measured using the Perceived Learning Scale (Kay and Knaack, 2009). Students responded to five items such as "Working with the online simulation environment helped me learn Microsoft Office applications (i.e., Word and Excel)." The internal reliability of these items was also good $(\alpha=0.86)$. Perceived learning entered the structural model as a latent variable with five indicators.

Lastly, open response items were used to gather insights about students' experiences with and perceptions of the OSE. Sample questions included "What did you like most/least about the online simulation environment?" and "What do 
you think about the effectiveness of the online simulation environment to learn Microsoft Office applications?".

\section{Results}

\section{Quantitative results}

Table 1 below presents the descriptive statistics for all variables included in the model. Mean scores ranged between 2.39 and 3.93 for directly observed variables, while standard deviation scores were in the range of $0.77-1.06$ for these variables.

\section{Measurement model}

A confirmatory factor analysis through SEM approach was conducted to assess the validity of the observed variables that were used to create the hypothesized structural relationship. The researchers used Maximum Likelihood (ML) estimation method for the factor analysis. The goodness of fit statistics showed good model fit (see Table 2). The parameter estimates also indicated that the observed variables entered in the model loaded significantly onto their identified latent variables (see Table 3). Thus, the researchers proceeded with the structural model analysis.

Table 1 Descriptive statistics of the items in the measure

\begin{tabular}{llllllllllll}
\hline & PEU & SAT1 & SAT2 & SAT3 & SAT4 & SAT5 & PL1 & PL2 & PL3 & PL4 & PL5 \\
\hline Mean & 3.03 & 3.34 & 2.39 & 2.79 & 2.93 & 3.68 & 3.89 & 3.72 & 3.93 & 3.78 & 3.88 \\
SD & 0.30 & 1.06 & 0.96 & 1.01 & 0.87 & 0.90 & 0.77 & 0.85 & 0.87 & 0.81 & 0.78 \\
PEU & & & & & & & & & & & \\
SAT1 & $0.30 \mathrm{~b}$ & & & & & & & & & & \\
SAT2 & $0.45 \mathrm{~b}$ & $0.49 \mathrm{~b}$ & & & & & & & & & \\
SAT3 & $0.39 \mathrm{~b}$ & $0.50 \mathrm{~b}$ & $0.64 \mathrm{~b}$ & & & & & & & \\
SAT4 & $0.33 \mathrm{~b}$ & $0.45 \mathrm{~b}$ & $0.38 \mathrm{~b}$ & $0.45 \mathrm{~b}$ & & & & & & \\
SAT5 & $0.22 \mathrm{~b}$ & $0.47 \mathrm{~b}$ & $0.31 \mathrm{~b}$ & $0.40 \mathrm{~b}$ & $0.31 \mathrm{~b}$ & & & & & \\
PL1 & $0.28 \mathrm{~b}$ & $0.34 \mathrm{~b}$ & $0.29 \mathrm{~b}$ & $0.26 \mathrm{~b}$ & $0.25 \mathrm{~b}$ & $0.25 \mathrm{~b}$ & & & & \\
PL2 & $0.37 \mathrm{~b}$ & $0.31 \mathrm{~b}$ & $0.31 \mathrm{~b}$ & $0.24 \mathrm{~b}$ & $0.28 \mathrm{~b}$ & $0.29 \mathrm{~b}$ & $0.63 \mathrm{~b}$ & & & \\
PL3 & $0.23 \mathrm{~b}$ & $0.33 \mathrm{~b}$ & $0.19 \mathrm{~b}$ & $0.20 \mathrm{~b}$ & $0.17 \mathrm{a}$ & $0.33 \mathrm{~b}$ & $0.46 \mathrm{~b}$ & $0.50 \mathrm{~b}$ & & \\
PL4 & $0.28 \mathrm{~b}$ & $0.39 \mathrm{~b}$ & $0.31 \mathrm{~b}$ & $0.33 \mathrm{~b}$ & $0.24 \mathrm{~b}$ & $0.37 \mathrm{~b}$ & $0.59 \mathrm{~b}$ & $0.49 \mathrm{~b}$ & $0.41 \mathrm{~b}$ & & \\
PL5 & $0.30 \mathrm{~b}$ & $0.41 \mathrm{~b}$ & $0.30 \mathrm{~b}$ & $0.37 \mathrm{~b}$ & $0.30 \mathrm{~b}$ & $0.34 \mathrm{~b}$ & $0.75 \mathrm{~b}$ & $0.60 \mathrm{~b}$ & $0.48 \mathrm{~b}$ & 0.72 \\
\hline
\end{tabular}

$\mathrm{PEU}=$ Perceived ease of use SAT $=$ Satisfaction $\mathrm{PL}=$ Perceived learning

${ }^{a}$ Correlation is significant at the 0.05 level (2-tailed)

${ }^{\mathrm{b}}$ Correlation is significant at the 0.01 level (2-tailed) 
Table 2 Fit Indices for the measurement model

\begin{tabular}{lcll}
\hline Model fit index & Value & Acceptable values & Reference \\
\hline$\chi^{2}$ & 77.38 & N/A & N/A \\
$\chi^{2 / \mathrm{df}}$ & 2.28 & $0 \leq \chi^{2} / \mathrm{df} \leq 3$ & Kline, 2011 \\
CFI & 0.95 & $0.95 \leq \mathrm{CFI} \leq 1.00$ & Hu \& Bentler, 1995 \\
RMSEA & 0.08 & $0 \leq \mathrm{RMSEA} \leq 0.08$ & Browne \& Cudeck, \\
& & & $1993 ;$ MacCallum \\
SRMR & 0.05 & $0 \leq$ SRMR $\leq 0.08$ & et al., 1996 \\
\hline
\end{tabular}

Table 3 Results of the measurement model (Standardized-STDYX)

\begin{tabular}{llllll}
\hline Latent Variable & Item & Estimate & Std. Error & Est./S.E & R2 \\
\hline Satisfaction & & & & & \\
& S1 & 0.718 & 0.044 & $16.245 \mathrm{a}$ & $0.516 \mathrm{a}$ \\
& S2 & 0.719 & 0.043 & $16.549 \mathrm{a}$ & $0.517 \mathrm{a}$ \\
& S3 & 0.769 & 0.040 & $19.106 \mathrm{a}$ & $0.592 \mathrm{a}$ \\
& S4 & 0.581 & 0.053 & $10.960 \mathrm{a}$ & $0.338 \mathrm{a}$ \\
& S5 & 0.547 & 0.056 & $9.720 \mathrm{a}$ & $0.299 \mathrm{a}$ \\
Perceived Learning & & & & \\
& PL1 & 0.820 & 0.028 & $29.545 \mathrm{a}$ & $0.672 \mathrm{a}$ \\
& PL2 & 0.698 & 0.040 & $17.418 \mathrm{a}$ & $0.487 \mathrm{a}$ \\
PL3 & 0.560 & 0.051 & $10.981 \mathrm{a}$ & $0.313 \mathrm{a}$ \\
& PL4 & 0.764 & 0.033 & $23.204 \mathrm{a}$ & $0.583 \mathrm{a}$ \\
& PL5 & 0.902 & 0.021 & 43.288 & $0.814 \mathrm{a}$ \\
\hline
\end{tabular}

${ }^{\mathrm{a}} p<0.01$

\section{Structural model}

In this study, satisfaction with the OSE was proposed as a mediating variable, which is assumed to account for some or all of the effects of perceived ease of use on perceived learning. The mediational effects of satisfaction were tested using the procedure established by Baron and Kenny (1986). The researchers used Maximum Likelihood (ML) estimation method for the structural analysis.

The goodness-of-fit indices for the structural model were within the acceptable range $\left(\chi^{2}=93.22, \chi^{2} / d f=2.22, \mathrm{CFI}=0.95, \mathrm{RMSEA}=0.08, \mathrm{SRMR}=0.05\right)$. Figure 2 shows the standardized test results of the hypothesized structural model. The results indicated that three of the four hypothesized relationships were in the hypothesized direction and statistically significant.

- H1. Perceived ease of use of the OSE was not significantly associated with perceived learning $(\beta=0.104, p=0.17)$.

- H2. Perceived ease of use of the OSE was significantly and positively associated with satisfaction with the OSE $(\beta=0.515, p<0.001)$. 


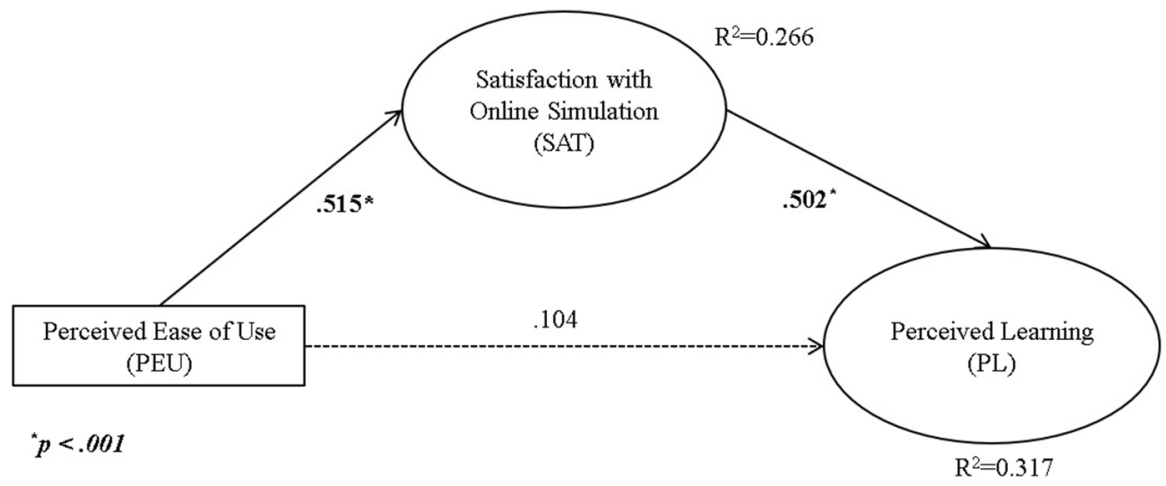

Fig. 2 Results of the structural model analysis

- H3a. Satisfaction with the OSE was significantly and positively associated with perceived learning $(\beta=0.502, p<0.001)$.

- H3b. Satisfaction with the OSE mediated the effects of perceived ease of use on perceived learning $(\beta=0.259, p<0.001)$.

Examining the results of $\mathrm{H} 1$ and $\mathrm{H} 3 \mathrm{~b}$ together, the hypothesized structural model supported the relationship between perceived ease of use of the OSE and perceived learning. However, this relationship was indirect and fully mediated by satisfaction with the OSE (total effect estimate $=0.363, p<0.001$ ). According to the $\mathrm{R}^{2}$ estimates, $32 \%$ of the variance in perceived learning was explained by satisfaction with the OSE and perceived ease of use (indirectly). Perceived ease of use explained $27 \%$ of the variance in satisfaction with the OSE.

\section{Qualitative results}

Analysis of the students' responses $(\mathrm{N}=215)$ to open-ended questions revealed valuable insights about their experiences with the OSE. When asked "Did [online simulation environment] help you learn how to use Microsoft Office applications better than you would have without it? If yes, How? Otherwise, what do you see to be its weaknesses?", most of the students $(n=185)$ mentioned that the OSE was beneficial to their learning of Microsoft Office applications. The remaining students $(n=30)$, however, mentioned that they did not find the OSE effective in helping them learn Microsoft Office applications; or they were neutral about the benefits of the OSE in terms of its impact on their learning. In most of the cases $(n=24)$, these were the students who had previous experience with and knowledge of Microsoft Office applications. 


\section{Improving information technology skills}

The students appreciated learning new features, shortcuts, and alternative ways of accomplishing tasks. Using the OSE helped the students get a thorough understanding of how to use the Microsoft Office applications. Many students $(n=122)$ expressed that the OSE helped them learn new features of the applications, shortcuts and alternative ways of accomplishing tasks, and reinforce the use of previously learned but not frequently used features. Among these students, many $(n=62)$ appreciated the opportunity to learn "things that [they] have never done" and "features [they] did not know existed." Furthermore, one student, who had previous experience with the Microsoft Office applications, mentioned that the OSE "helped [him or her] identify more things office can do." Another experienced user of the Microsoft Office applications wrote, "I still learned new things and got practice on some I don't use often."

On the other hand, several students $(n=10)$ were concerned that what they learned using the OSE would not be retained in the future due to the decontextualized nature of the simulation-based assignments. For example, one student wrote, "It did not give the purpose of the actions being performed. It did not put anything into real life situations." Another student shared the same concern by expressing, "I don't think I will remember much of what I learned that I did not know before because I had no reference of how I could use it in the real world." One student emphasized the need for a learning experience that connects to real world as "we need to do projects for homework that this would help learn it not just go through the motions." Overall, the students found the OSE effective in improving their information technology skills. However, negative cases raised an important concern about the necessity to connect practice activities to real-life situations for sustaining students' satisfaction.

\section{The way practice designed within the OSE}

The students valued the step-by-step, repetitive hands-on practice opportunity the OSE provided. In general, many students $(n=65)$ found the OSE effective because it exactly showed them "how to do things." Yet, what is more valued by students was the opportunity to practice skills hands-on in a step-by-step, repetitive manner. One student expressed that the OSE helped him or her learn the skills "by showing the steps and letting [him or her] perform them." Similarly, several students $(n=17)$ stated that the OSE "was the best way to learn Microsoft programs hands down"; "helped me to figure out things on my own"; "helped a lot because I was doing the work myself [which] made me learn how to do different things in the programs"; and "it helped me work my way through." In addition to hands-on practice, step-bystep structure of the assignments and repetitiveness of the tasks were emphasized as beneficial when learning information technology skills. For instance, one student described the learning process as "very step-by-step and has just enough repetition to drill the skill into habit." Another student wrote, "It made you actually do the steps hands on right then ... and not just once you had to use the steps in various different ways." Although this repetitiveness was perceived as a beneficial strategy for 
the most part, students raised concerns about this as well, especially when learning simpler tasks that are within close proximity in time. One student mentioned how the OSE stressed "simple concepts that one should be able to grasp without constant repetition" and another suggested "reincorporating things later" in different lessons to eliminate the possible demotivating effects of constant repetitiveness in the same lessons. Moreover, several students $(n=17)$, especially those who had previous experience with the Microsoft Office applications, mentioned completing the tasks "using [their] preferred methods" or "the methods [they] are most comfortable with" as opposed to completing tasks using the methods as the objectives of the lesson required. Where applicable, experienced learners wanted to have the flexibility of skipping tasks using the shortcuts instead of following the step-by-step instructions.

\section{Effectiveness of help provided by the OSE}

The OSE provided students with several instructional support features (i.e., Hint, Show Me, and Save for Later) as they were completing assignments. The students' perceptions about the effectiveness of the instructional support features of were positive overall. When asked about the effectiveness of the instructional support (i.e., Hint, Show Me, and Save for Later) provided by the OSE, 94 students indicated that they preferred using the Hint feature whereas only 21 students preferred using the Show Me feature as they found their preferred help strategy more effective than the other one in supporting their learning within the OSE. In addition, 91 students mentioned that they found both features very effective in supporting their learning experience, and nine students expressed that they found these features not effective in helping them gain information technology skills. Providing step-by-step guidance as students work through the steps of an assignment was the most referred reason for using Hint as students' preferred help strategy. Furthermore, several students $(n=26)$, especially those who found both strategies equally effective, mentioned that they chose the Show Me feature when the information provided by Hint did not help them understand how to accomplish the steps. Table 4 below presents a synthesis of why students preferred to use Hint or Show Me as the main help seeking strategy.

As students described their experiences with the Hint and Show Me features, they also mentioned the issues they experienced and the aspects of these support features that might have influenced their satisfaction with the OSE and the perceptions about their learning. First, the lack of clarity in directions at times made it difficult for students to understand what needed to be accomplished for a step. For example, one student wrote, "The directions for each step are sometimes confusing." Another student mentioned, "sometimes it was hard to tell what they were talking about and multiple times I got frustrated with the software not giving clear directions". These quotes indicated that lack of clear directions was a factor causing frustration while students were trying to complete the steps. Second, the Hint feature did not allow students to pass a step until they accomplished the objective of the step accurately, which caused frustrations as the number of unsuccessful attempts increased. One student mentioned, “... if you could not complete a step it would not let you skip it or move on. It became very frustrating at times." Another student mentioned how he 
Table 4 Reasons for preferring to use Hint and Show Me

\begin{tabular}{|c|c|}
\hline Hint & Show Me \\
\hline $\begin{array}{l}\text { Hint allowed students to work through the steps } \\
\text { (i.e., hands-on practice with step-by-step guid- } \\
\text { ance) }\end{array}$ & $\begin{array}{l}\text { Show Me was helpful and preferred when Hint } \\
\text { did not provide enough information to complete } \\
\text { the task }\end{array}$ \\
\hline $\begin{array}{l}\text { Hint helped students figure out how to accomplish } \\
\text { a task by providing guidance on completing the } \\
\text { steps that form the task }\end{array}$ & $\begin{array}{l}\text { Show Me was faster than Hint when assignments } \\
\text { did not contain too many steps }\end{array}$ \\
\hline $\begin{array}{l}\text { When the tasks required precision (e.g., dragging } \\
\text { off or resizing an object, capitalization of a letter), } \\
\text { Hint was more effective because it was easy and } \\
\text { clear to follow what should be done }\end{array}$ & $\begin{array}{l}\text { Show Me demonstrated all the steps of an assign- } \\
\text { ment in a sequential manner }\end{array}$ \\
\hline $\begin{array}{l}\text { Hint allowed students to control the pace because of } \\
\text { its step-by-step structure. Students had the oppor- } \\
\text { tunity to wait as much as they wanted before } \\
\text { moving to the next step }\end{array}$ & $\begin{array}{l}\text { Show Me allowed students to view what should be } \\
\text { achieved as the final product }\end{array}$ \\
\hline \multicolumn{2}{|l|}{$\begin{array}{l}\text { The directions to accomplish the tasks were broken } \\
\text { into steps, so students did not have to wait until } \\
\text { they heard and watched the whole instruction }\end{array}$} \\
\hline $\begin{array}{l}\text { Hint allowed students to spend more time perform- } \\
\text { ing the steps than watching what to do }\end{array}$ & \\
\hline
\end{tabular}

or she "did exactly what the hint instructions said and it would keep saying incorrect". Third, the preciseness of the actions was mentioned very often $(n=37)$ as the main reason for not being able to complete a step. As one student wrote, "Sometimes the measurements were too precise and it would never allow me to move on unless I had them exact." Another student wrote, "On the drag ones or the moves I would not do it exactly right, but would be in the area and it would make me move or drag it again. On one assignment I did this 7 times". These student quotes clearly show that after several inaccurate attempts, students started to get frustrated. Fourth, several students $(n=18)$ expressed that the Show Me feature did not include a visual cue indicating where the mouse clicks were taking place, which made it hard for them to follow. One student mentioned that the Show Me feature "tells the person what to click, but does NOT highlight WHAT you're supposed to be clicking on". Another student explained that he or she did not like using the Show Me feature because it "never actually showed [him or her] where I was supposed to click". Lastly, several students $(n=18)$ expressed their concerns about the control they had over the Hint and Show Me features. For instance, one student noted, "there is no way to end the hint program" once switched to it. Another student wrote, "When you understand a concept, I would like to be able to stop the hint or show me at any time." In Table 5, we provide a synthesis of the issues students experienced while they were utilizing the Hint and Show Me features.

Another instructional support feature the OSE provided was Save for Later. One hundred eighty-one students found this feature effective and useful; six students found it not effective; and 28 of them reported not using this feature. There were both positive and negative feelings about the effectiveness of this support feature. Several students $(n=30)$ indicated that the Save for Later feature was 
Table 5 Most common issues students experienced while utilizing Hint and Show Me

\begin{tabular}{|c|c|}
\hline Hint & Show Me \\
\hline $\begin{array}{l}\text { Students got frustrated when they could not pass } \\
\text { a step after attempting multiple times due to the } \\
\text { inaccuracy of their actions (e.g., preciseness) }\end{array}$ & $\begin{array}{l}\text { Show Me did not demonstrate how to complete } \\
\text { individual steps, rather it demonstrated the whole } \\
\text { task or final product. This became problematic, } \\
\text { especially when the tasks required precision }\end{array}$ \\
\hline $\begin{array}{l}\text { Lack of clarity in directions sometimes made it } \\
\text { difficult for students to understand what needed } \\
\text { to be accomplished }\end{array}$ & $\begin{array}{l}\text { There was no visual cue (e.g., mouse cursor mov- } \\
\text { ing) when the Show Me demonstrations were } \\
\text { running, which made it difficult for the students to } \\
\text { follow the steps }\end{array}$ \\
\hline $\begin{array}{l}\text { Once entered into the Hint mode, students needed } \\
\text { to complete all the steps, even if assistance was } \\
\text { needed for one small step }\end{array}$ & $\begin{array}{l}\text { Showing all the steps at once made it difficult for } \\
\text { some students to memorize the steps when they } \\
\text { needed to perform them, which resulted in watch- } \\
\text { ing the Show Me demonstrations multiple times }\end{array}$ \\
\hline $\begin{array}{l}\text { When students got stuck on a step, they could not } \\
\text { move forward until they accurately completed } \\
\text { the step }\end{array}$ & $\begin{array}{l}\text { When assignments had too many steps, it took too } \\
\text { long for students to watch the whole demonstra- } \\
\text { tion. Students also expressed that time spent } \\
\text { demonstrating simple steps or steps that were } \\
\text { practiced multiple times already was too much }\end{array}$ \\
\hline $\begin{array}{l}\text { After going through the steps one-by-one with } \\
\text { the Hint, completing the same steps again was } \\
\text { perceived repetitive and unnecessary }\end{array}$ & $\begin{array}{l}\text { Students did not have control over the Show Me } \\
\text { demonstration. They expressed the need for being } \\
\text { able to pause the demonstration or close it out at } \\
\text { any time }\end{array}$ \\
\hline $\begin{array}{l}\text { Occasionally, the OSE did not respond to students' } \\
\text { actions }\end{array}$ & $\begin{array}{l}\text { When demonstrating a task, students sometimes felt } \\
\text { Show Me skipped steps and did not fully show } \\
\text { them how it accomplished the objectives } \\
\text { Show Me forced students to watch the entire } \\
\text { demonstration even if they needed to get help for } \\
\text { a small part } \\
\text { The narration was too fast to follow at times } \\
\text { Occasionally, the OSE did not respond to students' } \\
\text { actions }\end{array}$ \\
\hline
\end{tabular}

especially beneficial when assignments were too long to complete at one sitting. For example, one student wrote, "It allowed me to take breaks and clear my mind." Another student stated, "It was a HUGE help. There were very few times that I have time to finish a whole section at once ... If you could not save the project, you'd have to restart all over again." However, several students $(n=15)$ expressed their frustrations with the Save for Later feature as it did not save the exact point where the students left off. Instead, it took the students to the beginning of the step they were working on, which resulted in redoing some of the tasks they already completed. This inconvenience caused some students to quit utilizing this feature. For instance, one student stated, "I had my worked erased twice ... so I never used it again." Another student shared the same concern, "If I saved something, and tried to retrieve it later, I always had to completely redo the entire module, which was frustrating." In one case, a student failed to revisit a partially completed assignment after using the Save for Later feature. Although such an issue was mentioned by one participant only, we found this 
case interesting because this could likely happen to many students with their busy schedules.

\section{Discussion and conclusion}

In this study, we explored college students' experiences with an online simulation environment (OSE) in gaining information technology skills. Results from the SEM analysis supported all but one hypothesized relationships between ease of use, satisfaction with the OSE, and perceived learning. In contrast to what was proposed in hypothesis one, our findings suggested that perceived ease of use did not have a direct effect on perceived learning. This finding supports the previous research suggesting that perceived ease of use does not predict perceived learning directly (Arbaugh, 2005; Arbaugh and Duray, 2002; Thomas, Parsons, and Whitcombe, 2019). However, perceived ease of use influenced satisfaction with the OSE and had an indirect effect on perceived learning through satisfaction with the OSE (i.e., mediation effect). This indicates that the easier the students find the OSE to use, the more satisfied they would be with their learning experiences within the OSE, which in turn, would enhance their perceived learning (Pérez-Pérez et al., 2020). Similar findings were reported in previous research on the relationship between perceived ease of use and satisfaction with OLS use (Arbaugh, 2005; Joo et al., 2011; Mtebe \& Raphael, 2018; Sun et al., 2008). In addition, consistent with previous studies, satisfaction with the OSE was found to have a direct effect on perceived learning (Cakir and Solak, 2014; Ifinedo et al., 2018; Islam, 2013; Karimi and Ahmad, 2013; Pérez-Pérez et al., 2020). This result reinforces the argument that learners who are satisfied with the OSE would benefit more from it when gaining information technology skills. Together, perceived ease of use (indirect) and satisfaction with the OSE (direct) explained $32 \%$ of the variance in perceived learning, which provides evidence in demonstrating how the students' experiences related to their use of an OSE might interact with their satisfaction, and thus influence their perceptions about the effectiveness of the learning environment in facilitating their learning.

To further explore the students' experiences, we considered the qualitative findings focusing on issues related to the use of and satisfaction with the OSE. We noticed that the frustrations caused by the issues related to the students' use of the OSE influenced their satisfaction with the OSE, and thus their perception about the effectiveness of the OSE in gaining information technology skills. Experiencing technical issues while trying to complete an assignment (e.g., software not responding), not being able to accomplish the objective of a step due to the precision required by the task (e.g., resize an object to the exact measures), inflexibility of certain features of the OSE (e.g., not being able to exit Hint or Show Me once launched), and the way certain aspects of the OSE designed to work (e.g., no visual cue in Show Me or not starting from where left off after using Save for Later) were the most common issues related to the students' use of the OSE, which may have influenced their satisfaction with the learning environment. These findings align with the results of a recent study by Pérez-Pérez et al. (2020) that a learning system's quality (e.g., reliability, accessibility) is an important factor influencing 
students' satisfaction with the learning system. To sum up, the issues related to a learning system's functionality and quality may cause learners to experience frustration, which may also impede their learning experience and satisfaction (Ceaparu et al., 2004; Keller, 2008; Lazar et al., 2006).

In addition to these, there were issues related to the design of the learning activities, which may have influenced the students' satisfaction with the OSE directly. For instance, the assignments were broken into multiple steps, each of which could be accomplished by completing several sub-tasks. Because the OSE did not adapt to the knowledge level of the students, they had to complete some tasks or steps multiple times in different assignments. When this was combined with lengthy assignments, it may have impacted the students' satisfaction with the OSE because the students could perceive this as unnecessary repetition of tasks that are already practiced, especially when the tasks were relatively simple (e.g., close the program).This finding corroborates with the findings of Flores et al. (2012), where some students felt dissatisfied with the long and repetitive assessments when learning about probability with an OLS. This result could partially be explained by the expertise reversal effect that as learners gain knowledge and skills in a domain, instructional strategies and support designed for novices may not work for those with some expertise (Kalyuga, 2009). Moreover, without knowing the purpose of the assignments and how the knowledge and skills gained could be used in the real world, the students may have not perceived the repetitive tasks in each assignment relevant to them, and thus, considered them as just motions to go through. Consequently, the completion of assignments may have not led to a feeling of satisfaction for some students. As Keller (2010) suggests, to improve or sustain students' feelings of satisfaction as they accomplish learning tasks, the tasks should be perceived as meaningful and relevant to them.

\section{Recommendations}

In the light of the reported findings, this study offers several recommendations regarding the design of OSEs. First, the students value the availability of guidance and support features in OSEs; however, they also value having more control and flexibility when using such features of OSEs. Therefore, the designers of these environments should consider strategies that would provide more freedom to students while they utilize such features as Hint or Show Me. At a minimum, the students should be able to exit from a mode (e.g., demonstration) at any time without watching the whole demonstration or going through all of the steps. In addition, while watching a Show Me demonstration, the students should be able to pause the demonstration, so they can process the presented information in small chunks. Furthermore, for both Hint and Show Me features, the students can be provided with a list of steps they need help with to help them focus on correcting those steps only. This would eliminate spending unnecessary time watching or going through the steps that were already completed.

Regarding the design of the Show Me and Hint features, the system designers should consider implementing visual cues to guide students' attention as the 
demonstration plays. This would allow students to follow the demonstration without investing unnecessary cognitive effort to figure out where to focus on. In addition, the way the Hint feature is designed usually requires the students to complete the assignment steps twice: (1) as they work through the steps with step-by-step guidance and (2) as they complete the steps without guidance upon using the Hint. This, however, might be perceived as redundant since both experiences are close within proximity. Instead of requiring students to complete the same steps in the same practice task after using the Hint, the steps can be embedded in later practice tasks.

Finally, the students perceived that the lengthy assignments (i.e., number of steps to be completed) and practicing the same steps repetitively were time consuming and unnecessary. However, this perception might change depending on the skill and knowledge level of students. Therefore, adapting to students' mastery levels might provide the best learning trajectory for each individual, which can also eliminate the repetitive practice of the same steps for those who already demonstrated competence in specific skills. In addition, the students would like to know the purpose of the assignments and how they can utilize the knowledge and skills they gain in real life. Therefore, instructional designers should consider situating assignments in real life contexts where the mastered knowledge and skills could possibly be used. For this, possible scenarios from the workplace or academic courses may be provided as examples at the beginning of each assignment.

\section{Limitations and future research}

As with any research study, this study has some limitations as well. First, we only focused on ease of use, satisfaction with the OSE, and perceived learning as our primary objective was to explore college students' experiences with an OSE in relation to these factors. Other characteristics of technology (e.g., media attributes) and learners (e.g., prior experience) can be incorporated into the model in future research. In addition, the factors that might mediate the effects of perceived ease of use of an OLS and satisfaction with the system were not of interest in this study. Future research might consider including system- or learner-related factors to enhance the explanatory power of the present model. Second, the current study used self-reported learning instead of performance scores because the students had unlimited attempts while practicing with the OSE. While the use of perceived learning is not uncommon in educational research, there may be discrepancies between students' perceived (i.e., self-reported) and actual learning (e.g., quiz, exam score, performance test) depending on how perceived and actual learning are measured. Thus, future studies might consider measuring task performance for actual learning and using this as the outcome variable in the model. Measuring learning on performance would also allow testing the effects of perceived ease of use and satisfaction with the OSE on the transfer of learning, which would demonstrate whether any of the learning gains can be sustained and applied in other contexts. Third, this study was conducted with undergraduate students who used an OSE to practice Microsoft Office applications in an information technology course. Because every learning tool is designed for a specific subject area with a target learner population in 
mind, they may offer unique features and learning interactions that are context specific. In addition, the nature and affordances of online simulations may vary from context to context (e.g., low fidelity vs. high fidelity, 2D vs 3D, concept-focused vs. system-focused) (Thisgaard and Makransky, 2017). Therefore, the findings of this study may not be generalized directly to other OSEs designed for such subject areas as chemistry, biology, business, etc. Therefore, future research might focus on exploring students' experiences with OSEs in other subject areas and courses where instructional simulations have been greatly utilized.

\section{Conclusion}

OSEs have been widely adopted in higher education in recent years. However, research focusing on the students' experiences with these environments is limited. Although OSEs are an effective instructional strategy in facilitating learning, the students' perceptions about the effectiveness of OSEs might be influenced by their satisfaction with some aspects of the OSEs. The results of this study provided evidence that both satisfaction with the learning environment and perceived ease of use are important factors explaining the students' perceived learning and that minor design issues can change the students' perceptions about the overall value of OSEs and their useful features. Thus, seeking opportunities to gauge the students' experiences related to their use of OSEs and specific instructional support features would be beneficial for the educators and designers of OSEs to further improve the students' learning experiences within these environments.

\section{Appendix}

\section{Open Response Items}

- What do you think about the effectiveness of the online simulation environment to learn Microsoft Office applications?

- What do you think about the effectiveness of the Hint feature?

- What do you think about the effectiveness of the Show Me feature?

- What do you think about the effectiveness of the Guidance/Instructions?

- What do you think about the effectiveness of the Feedback feature?

- What do you think about the effectiveness of the Save for Later feature?

- What did you like most about the online simulation environment?

- What did you like least about the online simulation environment?

- Did the online simulation environment help you learn how to use Microsoft Office applications (Word and Excel) better than you would have without it? If yes, How? Otherwise, what do you see to be its weaknesses? 


\section{Quantitative Items}

Perceived Learning (Adapted from Kay and Knack (2009)).

1. Working with the online simulation environment helped me learn Microsoft Office applications (Word, Excel).

2. The feedback for each step in the online simulation environment helped me learn Microsoft Office applications (Word, Excel).

3. The graphics and animations (Show Me) in the online simulation environment helped me learn Microsoft Office applications (Word, Excel).

4. The online simulation environment helped me possess new skills.

5. Overall, the online simulation environment helped me learn the Microsoft Office applications

Perceived Ease of Use (Adapted from Brooke (1996)).

1. I think that I would like to use the online simulation environment frequently.

2. I found the online simulation environment unnecessarily complex. (Reverse)

3. I thought the online simulation environment was easy to use.

4. I think that I would need the support of a technical person to be able to use the online simulation environment. (Reverse)

5. I found the various functions of the online simulation environment well integrated.

6. I would imagine that most people would learn to use the online simulation environment very quickly.

7. I found the online simulation environment very cumbersome to use. (Reverse)

8. I felt very confident using the online simulation environment.

9. I needed to learn a lot of things before I could get going with the online simulation environment. (Reverse)

Satisfaction with the OSE (Adapted from Keller (1993)).

1. Completing the assignments in the online simulation environment gave me a satisfying feeling of accomplishment.

2. I enjoyed using the online simulation environment so much that I would like to know more about the content.

3. I really enjoyed studying with the online simulation environment.

4. The wording of feedback after the exercises, or of other comments in the online simulation environment, helped me feel rewarded for my effort.

5. It felt good to successfully complete the assignments in the online simulation environment. 


\section{Declarations}

Conflicts of interest The authors declare that they have no conflict of interest.

\section{References}

Al-Azawei, A., \& Lundqvist, K. (2015). Learner differences in perceived satisfaction of an online learning: an extension to the technology acceptance model in Arabic sample. The Electronic Journal of e-Learning, 13(4), 408-426.

Al-Emran, M., Mezhuyev, V., \& Kamaludin, A. (2018). Technology acceptance model in m-learning context: a systematic review. Computers \&amp; Education, 125, 389-412. https://doi.org/10.1016/j. compedu.2018.06.008

Al-FraihatJoyMasadeh, D. M. R., \& Sinclair, J. (2020). Evaluating E-learning systems success: an empirical study. Computers in Human Behavior, 102, 67-86. https://doi.org/10.1016/j.chb.2019.08.004

Al-Rahmi, W. M., Yahaya, N., Aldraiweesh, A. A., Alamri, M. M., Aljarboa, N. A., Alturki, U., \& Aljeraiwi, A. A. (2019). Integrating technology acceptance model with innovation diffusion theory: an empirical investigation on student's intention to use E-learning systems. IEEE Access, 7, 26797-26809.

Alshurideh, M., Al Kurdi, B., Salloum, S. A. (2019). Examining the main mobile learning system driver's effects: A mix empirical examination of both the Expectation-Confirmation Model (ECM) and the Technology Acceptance Model (TAM). In International Conference on Advanced Intelligent Systems and Informatics p. 406-417. Springer, Cham.

Arbaugh, J. B. (2005). Is there an optimal design for on-line MBA courses? Academy of Management Learning \&amp; Education, 4(2), 135-149. https://doi.org/10.5465/amle.2005.17268561

Arbaugh, J. B. (2014). System, scholar or students? which most influences online MBA course effectiveness? Journal of Computer Assisted Learning, 30(4), 349-362. https://doi.org/10.1111/jcal.12048

Arbaugh, J. B., \& Duray, R. (2002). Technological and structural characteristics, student learning and satisfaction with web-based courses an exploratory study of two on-line MBA programs. Management Learning, 33(3), 331-347. https://doi.org/10.1177/1350507602333003

Babu, R., Singh, R. (2009). Evaluation of Web Accessibility and Usability from Blind User's Perspective: The Context of Online Assessment. AMCIS 2009 Proceedings, 623

Baker, R. S., D’Mello, S. K., Rodrigo, M. M. T., \& Graesser, A. C. (2010). Better to be frustrated than bored: the incidence, persistence, and impact of learners' cognitive-affective states during interactions with three different computer-based learning environments. International Journal of HumanComputer Studies, 68(4), 223-241.

Baron, R. M., \& Kenny, D. A. (1986). The moderator-mediator variable distinction in social psychological research: Conceptual, strategic, and statistical considerations. Journal of Personality and Social Psychology, 51(6), 1173-1182. https://doi.org/10.1037/0022-3514.51.6.1173

Benckendorff, P., Lohmann, G., Pratt, M., Reynolds, P., Strickland, P., Whitelaw, P. (2015). Enhancing student learning outcomes with simulation-based pedagogies. Australasian society for computers in learning and tertiary education (ascilite), 618-620.

Bentler, P. M. (1995). EQS structural equations program manual. Encino, CA: Multivariate Software.

Bolliger, D. U., \& Martin, F. (2018). Instructor and student perceptions of online student engagement strategies. Distance Education, 39(4), 568-583. https://doi.org/10.1080/01587919.2018.1520041

Bolliger, D. U., \& Martindale, T. (2004). Key factors for determining student satisfaction in online courses. International Journal on E-Learning, 3(1), 61-68.

Bradford, G. R. (2011). A relationship study of student satisfaction with learning online and cognitive load: Initial results. The Internet and Higher Education, 14(4), 217-226. https://doi.org/10.1016/j. iheduc.2011.05.001

Brooke, J. (1996). SUS-A quick and dirty usability scale. Usability Evaluation in Industry, 189(194), 4-7.

Browne, M. V., \& Cudeck, R. (1993). Alternative ways of assessing model fit. In K. A. Bollen \& J. S. Long (Eds.), Testing Structural Equation Models (pp. 136-162). Sage.

Cakir, R., \& Solak, E. (2014). Exploring the factors influencing e-learning of Turkish EFL learners through TAM. Turkish Online Journal of Educational Technology, 13(3), 79-87. 
Ceaparu, I., Lazar, J., Bessiere, K., Robinson, J., \& Shneiderman, B. (2004). Determining causes and severity of end-user frustration. International Journal of Human-Computer Interaction, 17(3), 333-356.

Chen, K. Z., Lowenthal, P. R., \& Bauer, C. (2016). Effectiveness and student perceptions of high-enrolment health studies online courses. Health Education Journal, 75(3), 343-357. https://doi.org/10. $1177 / 0017896915581060$

Chernikova, O., Heitzmann, N., Stadler, M., Holzberger, D., Seidel, T., \& Fischer, F. (2020). Simulation-based learning in higher education: a meta-analysis. Review of Educational Research, 90(4), 499-541.

Chiu, C. M., Hsu, M. H., Sun, S. Y., Lin, T. C., \& Sun, P. C. (2005). Usability, quality, value and e-learning continuance decisions. Computers \&amp; Education, 45(4), 399-416. https://doi.org/10.1016/j. compedu.2004.06.001

Dahlstrom, E., Brooks, D. C., Bichsel, J. (2014). The current ecosystem of learning management systems in higher education: Student, faculty, and IT perspectives. Louisville CO: EDUCAUSE Research Report

Davis, F. D. (1989). Perceived usefulness, perceived ease of use, and user acceptance of information technology. MIS Quarterly. https://doi.org/10.2307/249008

Davis, F. D., Bagozzi, R. P., \& Warshaw, P. R. (1992). Extrinsic and intrinsic motivation to use computers in the workplace. Journal of Applied Social Psychology, 22(14), 1111-1132. https://doi.org/10. 1111/j.1559-1816.1992.tb00945.x

Dumford, A. D., \& Miller, A. L. (2018). Online learning in higher education: exploring advantages and disadvantages for engagement. Journal of Computing in Higher Education, 30(3), 452-465. https:// doi.org/10.1007/s12528-018-9179-z

El-Masri, M., \& Tarhini, A. (2017). Factors affecting the adoption of e-learning systems in Qatar and USA: extending the unified theory of acceptance and use of technology 2 (UTAUT2). Educational Technology Research and Development. https://doi.org/10.1007/s11423-016-9508-8

Flores, R., Ari, F., Inan, F. A., \& Arslan-Ari, I. (2012). The impact of adapting content for students with individual differences. Journal of Educational Technology \&amp; Society, 15(3), 251-261.

Furtado, P. G. F., Hirashima, T., \& Hayashi, Y. (2019). The effect on new knowledge and reviewed knowledge caused by the positioning task in closed concept maps. Research and Practice in Technology Enhanced Learning, 14(1), 1-14.

Green, L. S., Inan, F. A., \& Denton, B. (2012). Examination of factors impacting student satisfaction with a new learning management system. Turkish Online Journal of Distance Education, 13(3), 189-197.

Haddad, F. S. (2018). Examining the effect of learning management system quality and perceived usefulness on student's satisfaction. Journal of Theoretical and Applied Information Technology, 96(23), 8034-8044.

Hallinger, P., \& Wang, R. (2020). The evolution of simulation-based learning across the disciplines, 1965-2018: a science map of the literature. Simulation \&amp; Gaming, 51(1), 9-32.

Hodges, C., Moore, S., Lockee, B., Trust, T., \& Bond, A. (2020). The difference between emergency remote teaching and online learning. Educause Review, 27, 1-12.

Hu, L., Bentler, P.M. (1995). Evaluating model fit. In R. H. Hoyle's (Eds) Structural Equation Modeling: Concepts, Issues, and Application, p. 76-99. Thousand Oaks, CA: Sage Publications.

Ifinedo, P., Pyke, J., \& Anwar, A. (2018). Business undergraduates' perceived use outcomes of moodle in a blended learning environment: the roles of usability factors and external support. Telematics and Informatics, 35(1), 93-102.

Iglesias, A., Moreno, L., Castro, E., \& Cuadra, D. (2014). Are accessible distance learning systems useful for all students? our experience with IMES, an accessible web-based learning system. International Journal of Web-Based Learning and Teaching Technologies, 9(1), 1-17. https://doi.org/10.4018/ ijwltt.2014010101

Islam, A. N. (2013). Investigating e-learning system usage outcomes in the university context. Computers \&amp; Education, 69, 387-399. https://doi.org/10.1016/j.compedu.2013.07.037

Joo, Y. J., Lim, K. Y., \& Kim, E. K. (2011). Online university student's satisfaction and persistence: examining perceived level of presence, usefulness and ease of use as predictors in a structural model. Computers \&amp; Education, 57(2), 1654-1664. https://doi.org/10.1016/j.compedu.2011. 02.008

Kalyuga, S. (2009). The expertise reversal effect. In: Managing cognitive load in adaptive multimedia learning, p. 58-80. IGI Global. 
Karimi, L., \& Ahmad, T. B. T. (2013). Perceived learning and satisfaction in a blended teacher education program: an experience of Malaysian teacher trainees. Contemporary Educational Technology, 4(3), 197-211.

Kay, R. H., \& Knaack, L. (2009). Assessing learning, quality and engagement in learning objects: the Learning object evaluation scale for students (LOES-S). Educational Technology Research and Development, 57, 147-168. https://doi.org/10.1007/s11423-008-9094-5

Kebritchi, M., Lipschuetz, A., \& Santiague, L. (2017). Issues and challenges for teaching successful online courses in higher education: a literature review. Journal of Educational Technology Systems, 46(1), 4-29. https://doi.org/10.1177/0047239516661713

Keller, J.M. (1983). Motivational design of instruction. In C.M. Reigeluth, eds, Instructional Design Theories and Models: An Overview of Their Current Status. Hillsdale, NJ: Erlbaum.

Keller, J.M. (1993). Manual for Instructional Materials Motivational Survey (IMMS). Tallahassee, FL.

Keller, J.M. (2010). Managing outcomes for satisfaction. In Motivational Design for Learning and Performance, p. 165-192. Springer, Boston, MA.

Keller, J. M. (2008). An integrative theory of motivation, volition, and performance. Technology, Instruction, Cognition, and Learning, 6(2), 79-104.

Kline, R. B. (2011). Principles and practice of structural equation modeling (3rd ed.). Guilford Press.

Lazar, J., Jones, A., Hackley, M., \& Shneiderman, B. (2006). Severity and impact of computer user frustration: a comparison of student and workplace users. Interacting with Computers, 18, 187-207.

Lowenthal, P. R., Nyland, R., Jung, E., Dunlap, J. C., \& Kepka, J. (2019). Does class size matter? an exploration into faculty perceptions of teaching high-enrollment online courses. American Journal of Distance Education., 33(3), 152-168. https://doi.org/10.1080/08923647.2019.1610262

MacCallum, R. C., Browne, M. V., \& Sugawara, H. M. (1996). Power analysis and determination of sample size for covariance structure modeling. Psychological Methods, 1, 130-149. https://doi.org/10. 1037/1082-989X.1.2.130

Makransky, G., Mayer, R. E., Veitch, N., Hood, M., Christensen, K. B., \& Gadegaard, H. (2019). Equivalence of using a desktop virtual reality science simulation at home and in class. Plos One, 14(4), e0214944.

Mayer, R. (2020). Multimedia learning (3rd eds). Cambridge University. https://doi.org/10.1017/97813 16941355

McGill, T. J., \& Klobas, J. E. (2009). A task-technology fit view of learning management system impact. Computers and Education, 52(2), 496-508. https://doi.org/10.1016/j.compedu.2008.10.002

Mohammadi, H. (2015). Investigating users' perspectives on e-learning: an integration of TAM and IS success model. Computers in Human Behavior, 45, 359-374. https://doi.org/10.1016/j.chb.2014.07. 044

Mtebe, J. S., Raphael, C. (2018). Key factors in learner's satisfaction with the e-learning system at the University of Dares Salaam, Tanzania. Australasian Journal of Educational Technology, 34(4). https://doi.org/10.14742/ajet.2993

Naveh, G., Tubin, D., \& Pliskin, N. (2012). Student satisfaction with learning management systems: a lens of critical success factors. Technology, Pedagogy and Education, 21(3), 337-350.

Nguyen, H., Pham, H., Vu, N., \& Hoang, H. (2020). Factors influencing students' intention to use e-learning system: a case study conducted in Vietnam. International Journal of Emerging Technologies in Learning (iJET), 15(18), 165-182.

Nunnally, J. C., \& Bernstein, J. H. (1994). Psychometric theory (3rd ed.). McGraw-Hill.

Ozkan, S., \& Koseler, R. (2009). Multi-dimensional students' evaluation of e-learning systems in the higher education context: an empirical investigation. Computers and Education, 53(4), 1285-1296. https://doi.org/10.1016/j.compedu.2009.06.011

Pérez-Pérez, M., Serrano-Bedia, A. M., \& García-Piqueres, G. (2020). An analysis of factors affecting students perceptions of learning outcomes with moodle. Journal of Further and Higher Education, 44(8), 1114-1129.

Persico, D., Manca, S., \& Pozzi, F. (2014). Adapting the technology acceptance model to evaluate the innovative potential of e-learning systems. Computers in Human Behavior, 30, 614-622. https://doi. org/10.1016/j.chb.2013.07.045

Rejón-Guardia, F., Polo-Peña, A. I., \& Maraver-Tarifa, G. (2020). The acceptance of a personal learning environment based on Google apps: the role of subjective norms and social image. Journal of Computing in Higher Education, 32(2), 203-233. 
Sahasrabudhe, S., Lockley, M. (2014). Understanding blind user's accessibility and usability problems in the context of myITlab simulated environment. Proceedings of the 20th Americas Conference on Information Systems.

Singh, V., \& Thurman, A. (2019). How many ways can we define online learning? a systematic literature review of definitions of online learning (1988-2018). American Journal of Distance Education, 33(4), 289-306. https://doi.org/10.1080/08923647.2019.1663082

Skinner, B. T. (2019). Making the connection: Broadband access and online course enrollment at public open admissions institutions. Research in Higher Education, 60(7), 960-999. https://doi.org/10. 1007/s11162-018-9539-6

Small, R. V., \& Venkatesh, M. (2000). A cognitive-motivational model of decision satisfaction. Instructional Science, 28(1), 1-22. https://doi.org/10.1023/A:1003574312599

Sun, P. C., Tsai, R. J., Finger, G., Chen, Y. Y., \& Yeh, D. (2008). What drives a successful e-Learning? an empirical investigation of the critical factors influencing learner satisfaction. Computers \&amp; Education, 50(4), 1183-1202. https://doi.org/10.1016/j.compedu.2006.11.007

Thisgaard, M., \& Makransky, G. (2017). Virtual learning simulations in high school: effects on cognitive and non-cognitive outcomes and implications on the development of STEM academic and career choice. Frontiers in Psychology, 8, 805.

Way, K. A., Burrell, L., D’Allura, L., \& Ashford-Rowe, K. (2021). Empirical investigation of authentic assessment theory: an application in online courses using mimetic simulation created in university learning management ecosystems. Assessment \&amp; Evaluation in Higher Education, 46(1), 17-35. https://doi.org/10.1080/02602938.2020.1740647

Weibel, D., Stricker, D., \& Wissmath, B. (2012). The use of a virtual learning centre in the context of a university lecture: factors influencing satisfaction and performance. Interactive Learning Environments, 20(1), 77-87. https://doi.org/10.1080/10494821003755502

Wu, J. H., Tennyson, R. D., \& Hsia, T. L. (2010). A study of student satisfaction in a blended e-learning system environment. Computers and Education, 55(1), 155-164. https://doi.org/10.1016/j.compedu. 2009.12.012

Yang, E., \& Dorneich, M. C. (2018). Evaluating human-automation etiquette strategies to mitigate user frustration and improve learning in affect-aware tutoring. Applied Sciences, 8(6), 895.

Publisher's Note Springer Nature remains neutral with regard to jurisdictional claims in published maps and institutional affiliations.

Fatih Ari is an Assistant Professor in the Learning Design and Technologies program at the University of South Carolina. His research interests include feedback design and delivery, adaptive learning systems, multimedia learning, and computer science education.

Ismahan Arslan-Ari is an Assistant Professor in the Learning Design and Technologies program at the University of South Carolina. She is also serving as Director of the South Carolina Center for Assistive Technology and Educational Research (SC-CATER). Her research mainly focuses on multimedia learning, human-computer interaction, the use of assistive technologies, and webbased learning systems.

Serdar Abaci is a Lecturer (Assistant Professor) in Data and Digital Literacies at the Moray House School of Education and Sport, the University of Edinburgh. His research interests include data and digital literacies, formative assessment and feedback, online learning, and adoption of teaching and learning technologies in K-12 and Higher Education contexts.

Fethi Ahmet Inan is a President's Excellence in Teaching Professor of Instructional Technology at Texas Tech University. His research interests are online learning, adaptive learning systems, individual differences, and integration of technology into various learning environments. 